\title{
Imagery ability in paired-associate and incidental learning'
}

\begin{abstract}
CAROLE H. ERNEST and ALLAN PAIVIO, University of Western Ontario, London, Canada
\end{abstract}

Subjects differing in imagery ability according to tests of spatial ability leamed a paired-associate $(P A)$ list in which either the stimulus or response members were Strooptype color-word compounds. Either the color name or the color served as the functional attribute. Imagen ability was unrelated to PA leaming, but high-imagery $S s$ were superior to low-imagery $S$ s in their incidental memory for the irrelevant components of the compound units. The effect was particularly strong in the second of two experiments.

Recent evidence (see Paivio, in press) has indicated that imagery, defined either as a stimulus (meaning) attribute or in terms of such experimental procedures as mnemonic instructions, can function as an effective mediator of recall. Whether the imagery hypothesis may be extended to encompass individual differences in imagery ability is of considerable theoretical import. Successful predictions of performance based on such differences would provide further convergent evidence that a common intervening process is involved whether imagery is defined by stimulus attributes, mnemonic instructions, or individual differences.

Much of the early research on the memory function of individual differences in imagery suggested that such differences, as measured by introspective reports and self-ratings of the vividness of images, is not related to accuracy of recall (see Oswald, 1962). Positive results using such measures have been reported only occasionally (e.g., Davis, 1932; Sheehan, 1966). Using a different approach, Kuhlman (1960) and Stewart (1965) recently obtained reliable relationships between imagery differences and learning and memory. The novel aspect of both studies was that imagery was defined in terms of objective scores on tests of spatial ability (see Barratt, 1953). Such an approach was utilized in the present research.

The purpose of this study originally was to investigate the role of imagery ability in the stimulus selection and associative phases of paired-associate (PA) learning. It was reasoned that when the stimulus terms in a PA-learning task are compounds consisting of both verbal and nonverbal components, high imagers will be superior to low imagers when instructed to use the nonverbal component as the functional stimulus (FS) and inferior when the FS is the verbal component. These predictions were based on the hypothesis that high imagers would be better able to extract the nonverbal stimulus cue and to use imagery as a mediator in learning. While these expectations received only weak support, the experiments reported here unexpectedly revealed that imagery was an important factor in incidental learning.

\section{EXPERIMENT 1}

Method

A PA list of eight pairs was constructed for each FS condition. In each list, the stimulus members were color names printed in congruent or incongruent colors (see Stroop, 1935) and the response members were nouns, matched in terms of frequency, concreteness, imagery, and meaningfulness (Paivio, Yuille, \& Madigan, 1968). The colors were: black, blue, brown, green, orange, pink, red, and yellow. The nouns were: flower, money, palace, picture, sugar, tower, valley, and window. Stimuli and responses were randomly paired with the restriction that the members of a pair not begin with the same letter or have any obvious meaningful association.

When the nonverbal (color) cue served as the FS, the eight color stimuli were embedded in only four color names-red, yellow, blue, and green-so that four of the color-word combinations were congruent and four were incongruent. The incongruent compound stimuli were red-brown (i.e., the word "red" printed in brown ink), yellow-black, blue-orange, and green-pink. A parallel list was constructed for the verbal cue, or word FS, condition by printing the eight color names in only four colors. The same color concept (word or ink color) served as the FS to the same response term in both lists.

Two-hundred sixty-three (263) introductory psychology students were administered an Imagery Test Battery consisting of Space Relations, the revised Minnesota Paper Form Board (MPFB), and the MPFB Questionnaire (Barratt, 1953). All raw scores were converted to standard scores and summed, giving each $\mathrm{S}$ a total standard score (TSS). Thirty-two Ss (16 males and 16 females) were then randomly selected from each upper and lower quartile of the TSS distribution and defined as high and low imagers, respectively. They were assigned at random to the two FS conditions with the restriction that males and females be equally represented in each FS and Imagery condition. The instructions stressed paying attention only to the color of the compound stimulus when learning each pair in the nonverbal FS condition, and to the word itself in the verbal FS condition. Any $S$ who had difficulty labeling the eight colors used in this experiment in a preexperimental test for color blindness was excluded from the study.

The two FS conditions were run alternately throughout each experimental day. Ss were tested in pairs, one $S$ coming from each imagery level. The PA lists were presented as $35 \cdot \mathrm{mm}$ slides projected on a screen. Eight alternating study and recall trials were administered, the exposure duration for both study and recall being $2 \mathrm{sec}$. The Ss were allowed $8 \mathrm{sec}$ to write their responses to each stimulus during recall. The order of the eight items during study and recall was randomized.

Upon completing the PA task, Ss were tested for incidental learning by having them write down the name or color (depending on the FS condition in which they had been tested) of the irrelevant or incidental aspect of the stimulus which was compounded with the FS.

The design for the PA study was a 2 by 2 by 2 by 2 by 8 multifactor design in which imagery (high and low), FS (color and word), and sex served as between-S variables, and congruency (congruent and incongruent) and trials (eight levels) were within-S variables. Trials was not a variable in the incidental-learning design.

\section{PA Learning}

Results and Discussion?

An analysis of variance revealed significant effects for $\mathrm{FS}(\mathrm{F}=22.47, \mathrm{df}=1 / 56$, $p<.001$ ) and the FS by Congruency interaction $(F=4.89$, df $=1 / 56, p<.05)$. Recall was significantly higher in the word condition $(\mathrm{X}=3.58)$ than in the color condition $(\bar{X}=3.12)$. Further analyses of the interaction unexpectedly revealed that responses to incongruent compound stimuli in the word condition were recalled significantly better than to congruent compound stimuli $(F=5.87$, df $=1 / 28$, $p<.05)$. Differences were in the reverse direction in the color condition, but were not significant. A significant Congruency by Trials interaction $(F=4.45, d f=7 / 392$, $\mathrm{p}<.001$ ) indicated that incongruent stimuli facilitated performance at Trial 1 , with a crossover occurring at Trial 2. There were no congruency differences on subsequent trials.

These results, although offering little support for the imagery predictions, do support previous findings that learning is retarded when word color serves as the functional cue (Kroll \& Grant, 1968). The discrepancy with findings that the incongruency of compound stimuli negatively influences performance (Kroll \& Grant 
Table 1

Mean Correct Recalls in Incidental Leaming (Experiment 1)

\begin{tabular}{llcc}
\hline FS & Imagery & \multicolumn{2}{c}{$\begin{array}{c}\text { Congruency } \\
\text { Incongruent }\end{array}$} \\
\hline \multirow{2}{*}{ Color } & High & 3.56 & 2.94 \\
& Low & 3.19 & 2.12 \\
\multirow{2}{*}{ Word } & High & 3.44 & 2.44 \\
& Low & 2.69 & 2.38 \\
\hline
\end{tabular}

1968; Saufley \& Underwood, 1964) may be attributable to the use of congruency as a within-S variable in the present study.

Incidental Learning

The mean number of correct recalls within each experimental condition are presented in Table 1 . The main effect of congruency was significant $(F=39.34$, $\mathrm{df}=1 / 56, \mathrm{p}<.001)$, incidental recall being facilitated when the components of the compound stimuli were congruent $(\bar{X}=3.22)$ rather than incongruent $(\bar{X}=2.47) .3$ The main effect of imagery level fell short of significance $(F=3.23$, $\mathrm{df}=1 / 56, \mathrm{p}<.10$ ). However, a significant interaction of imagery, FS, and congruency $(F=5.53, \mathrm{df}=1 / 56, \mathrm{p}<.05)$ revealed that recall was higher for high imagers in the word condition when stimuli were congruent, and in the color condition when stimuli were incongruent.

The results suggest that imagery plays a significant role in the perception and recall of incidental stimulus cues. Predictions based on imagery differences in PA learning, however, were not supported. Experiment 2 was conducted to further investigate the mediating-imagery hypothesis. Since nouns are more effective than adjectives as recall cues (Paivio, in press), it was predicted that by reversing the $S \cdot R$ terms of Experiment 1 so that nouns served as stimuli, as well as minimizing overlearning through a reduction in the number of trials presented, differences between imagers would be more pronounced in both the PA and incidental learning tasks.

\section{EXPERIMENT 2 \\ Method}

Forty university summer school students (16 males and 24 females) completed the Imagery Test Battery. Ss were defined as high or low imagers if their total standard scores were positive or negative, respectively. Five males and seven females were selected from each imagery level on the basis of their availability. 4

All Ss were tested under the nonverbal (color) response condition. The procedures of Experiment 1 were followed with the exceptions that S-R pairs were reversed and only four alternating study and recall trials were administered. The Ss were instructed to pay attention only to the color of the ink in which the response word was printed when learning each pair. After the PA task, Ss completed an incidental learning questionnaire.

\section{PA Learning}

\section{Results}

An analysis of variance with imagery, congruency, and trials as factors revealed significant - effects for trials $(F=27.84$, $\mathrm{df}=3 / 66, \quad \mathrm{p}<.001)$ and congruency $(F=13.36, d f=1 / 22, p<.01)$. Congruent compound responses were more easily learned $(\bar{X}=2.69)$ than incongruent compound responses $(\bar{X}=1.94)$, thus replicating the findings of Kroll \& Grant (1968). The main effect for imagery, although in the predicted direction, was not significant $(F=1.12$, df $=1 / 22)$.

Incidental Learning

The mean number of correct recalls of the irrelevant response component are given in Table 2. It can be seen that incidental recall is consistently much better for high imagers than for low imagers. The main effect is significant by an analysis of variance ( $F=9.40, d f=1 / 22, p<.01)$. Further, the incidental learning of all Ss was facilitated when the components of each response were congruent $(F=14.74, \mathrm{df}=1 / 22, \mathrm{p}<.001)$.

\section{DISCUSSION}

The results from Experiments 1 and 2 suggest that imagery plays a significant role in incidental visual learning. The effects of imagery appeared in interaction with FS and congruency in Experiment 1 and emerged as a significant main effect in Experiment 2, strongly suggesting that high imagery is an ability to represent both verbal and nonverbal visual cues in memory and to retrieve either equally well. Together with the Kuhlman (1960) and Stewart (1965) findings, the present results demonstrate that performance on objective spatial tasks, which reflect the ability to imaginally transform figural information, is predictive of visual memory in certain situations.

Table 2

Mean Correct Recalls in Incidental Learning (Experiment 2)

\begin{tabular}{lcc}
\hline Imagery & \multicolumn{2}{c}{ Congruency } \\
& Congruent & Incongruent \\
\hline High & 3.00 & 2.08 \\
Low & 1.75 & 0.67 \\
\hline
\end{tabular}

Moreover, considered along with evidence on the effect of imagery mnemonic instructions and of imagery as an item attribute (Paivio, in press), they suggest that, however imagery is defined, it is functionally related to learning and memory. We cannot conclude, however, that imagery ability, as measured in these studies, necessarily reflects precisely the same process as that defined by experimental manipulations or by word imagery. Also, the extent to which the conclusions from this study can be generalized to other incidental learning situations remains a critical question.

\section{REFERENCES}

BARRATT, P.E. Imagery and thinking. Australian Journal of Psychology, 1953, 5, 154-164.

DAVIS, F. C. The functional significance of imagery differences. Journal of Experimental Psychology, 1932, 15,630-661.

KROLL, N.E. A., \& GRANT, D. A. Cue selection in paired-associate and concept-learning paradigms. Journal of Verbal Learning \& Verbal Behavior, 1968, 7, 64-71.

KUHLMAN, C. K. Visual imagery in children. Unpublished doctoral dissertation, Radcliffe College, 1960.

OSWALD, I. Sleeping and waking. New York: Elsevier Publishing Company, 1962.

PAIVIO, A. Mental imagery in associative learning and memory. Psychological Review, in press.

PAIVIO, A., YUILLE, J. C., \& MADIGAN, S. Concreteness, imagery, and meaningfulness values for 925 nouns. Journal of Experimental Psychology (Monograph Supplement), 1968 , 76, 1-25.

SAUFLEY, W. H., \& UNDERWOOD, B. J. Cue-selection interference in paired-associate learning. Journal of Verbal Learning \& Verbal Behavior, 1964, 3, 474-479.

SHEEHAN, P. W. Functional similarity of imaging to perceiving: Individual differences in vividness of imagery. Perceptual \& Motor Skills, 1966, 23 . 1011-1033.

STEWART, J. C. An experimental investigation of imagery. Unpublished doctoral dissertation, University of Toronto, 1965.

STROOP, J. R. Studies in interference in serial verbal reaction. Journal of Experimental Psychology, 1935, 18,643-661.

$$
\text { NOTES }
$$

1. This research was supported by a National Research Council (NRC) of Canada Postgraduate Scholarship to the first author, an NRC Grant (APA-87) to the second author, and the University of Western Ontario Research Fund.

2. The effects of sex and trials and their interactions, unless of some theoretical interest, are not discussed.

3. Analyses of the actual responses given revealed that this effect could not be attributed to a response bias whereby Ss might reply congruently when doubtful of the correct response.

4. A measure of associative fluency, in troduced as a control for verbal ability, indicated that high and low imagers did not differ in their verbal production scores $(t=1.27, d f=22)$. 